\title{
Innovative and applied research on big data platforms of smart heritage
}

\author{
J. Qiu a ${ }^{\text {J. Li }}{ }^{\text {a }}$, H. Sun ${ }^{\text {a* }}$ \\ ${ }^{a}$ Beijing Re-Yuan Ming Yuan Company Limited, Haidian District Shangdi West Road Yard 41 NO.1, 100085, Beijing, China - \\ qiujie@thid.cn \\ ${ }^{a}$ Beijing Re-Yuan Ming Yuan Company Limited , Haidian District Shangdi West Road Yard 41 NO.1, 100085, Beijing, China - \\ lijiajuan@thid.cn \\ ${ }^{a}$ Beijing Re-Yuan Ming Yuan Company Limited , Haidian District Shangdi West Road Yard 41 NO.1, 100085, Beijing, China - \\ sunhuijiao@thid.cn
}

KEY WORDS: Smart heritage, Big data, Explanation

\begin{abstract}
:
Big data has huge commercial value and potential. Under the background of big data, a heritage site is faced with a number of questions and challenges such as, how to accelerate industrial innovation, benign competition and the creation of new business value. Based on the analysis of service data from the national archaeological site and park, Yuan Ming Yuan, this paper investigates the common problems of site management operations such as, inappropriate cultural interpretation, insufficient consumer demand and so on. In order to solve these operational problems, a new service system called the "one platform - three systems" was put forward. This system includes the smart heritage platform and three management systems: the smart heritage management system, the 3-O (Online-Offline-Onsite) service system and the digital explanation system. Combined with the 3-O marketing operation, the platform can realize bidirectional interaction between heritage site management units and tourists, which can also benefit visitors to the heritage site by explaining the culture and history of the heritage site, bring about more demand for cultural information and expand the social and economic benefits.
\end{abstract}

\footnotetext{
* Corresponding author
} 


\section{TRAVEL SERVICE STATUS UNDER THE BACKGROUND OF BIG DATA}

\subsection{The implication of big data}

With, Information and data that governments, enterprises, other social organizations and individuals are producing has exponentially exploded due to the development of the Internet, cloud computing and Internet technology. The IDC (Internet Data Center) predicts that by 2020 the world will have $35 \mathrm{ZB}$ of data $(1 \mathrm{ZB}=1$ billion $\mathrm{TB}$ or 1 trillion $\mathrm{G})$, which is 44 times more than 2009. This huge amount of data is referred to as "big data" and this much data is difficult for people to capture and manage in a reasonable time. Big data technologies have high information predictability and can accurately analyze the correlation between data through the analysis of data filtering.

\subsection{Digital museum construction abroad}

With the advent of the era of big data and expanding digitization, there is greater importance to the construction of digital museums both at home and abroad. In America, for example, the museum's collection, exhibition, and education work is taken as the continuation of a culture and its eventual spread. Digital museums have the characteristics of being both convenient and efficient and can realize more communication and sharing of resources with the public. Therefore, the digital museum is highly valued.

A questionnaire from the gallery directors association (table 1) shows that out of the top 10 museums, 7 museums have a higher number of Internet users, which is more than the number of visitors coming to the museum. The higher network access reflected in huge profits for the museum. The museum of modern art in New York in 2007 had a network turnover that reached $\$ 5.343$ million. This not only reflects the great importance that Americans attach to the construction of digital museum, but also reflects on the profound significance that digital museums bring. The success of the digital museum in America has a great significance to China's powerful and largescale museums.

\begin{tabular}{|c|c|c|c|c|}
\hline Name of the museum & $\begin{array}{c}\text { Site } \\
\text { visitors } \\
\text { (Ten } \\
\text { thousand) }\end{array}$ & $\begin{array}{c}\text { Web users } \\
\text { (Ten } \\
\text { thousand) }\end{array}$ & $\begin{array}{c}\text { network } \\
\text { marketing } \\
\text { income } \\
\text { ( } \mathbf{F} \text { Ten } \\
\text { thousand) }\end{array}$ & $\begin{array}{c}\text { network } \\
\text { marketing } \\
\text { spending } \\
\text { (₹ Ten } \\
\text { thousand) }\end{array}$ \\
\hline National art gallery & 470.7 & 1122.2 & unknown & unknown \\
\hline $\begin{array}{c}\text { The metropolitan } \\
\text { museum of art }\end{array}$ & 475.8 & unknown & 4032.9 & unknown \\
\hline $\begin{array}{c}\text { The modern art } \\
\text { museum }\end{array}$ & 256.2. & 619.7 & 3533 & 2906.8 \\
\hline $\begin{array}{c}\text { The Houston museum } \\
\text { of art }\end{array}$ & 160.3 & 66.1 & unknown & unknown \\
\hline $\begin{array}{c}\text { Los Angeles county } \\
\text { museum }\end{array}$ & 166.7 & 20.9 & 37.7 & 21.8 \\
\hline $\begin{array}{c}\text { The art institute of } \\
\text { Chicago museum }\end{array}$ & 154.3 & 181.4 & 1878.6 & 1414.4 \\
\hline J. Paul getty museum & 125.9 & 450.4 & 62.8 & 61.5 \\
\hline The Boston museum & 128.5 & 366.9 & 270.5 & unknown \\
\hline $\begin{array}{c}\text { Solomon R } \\
\text { guggenheim museum }\end{array}$ & 89.9 & 211.9 & 109.1 & 64.8 \\
\hline Hersh horn museum & 75.6 & 120.8 & unknown & unknown \\
\hline
\end{tabular}

Table 1: Online vs. Site visits to the top 10 American museums in 2007

\subsection{The current situation of domestic heritage sites in China}

The advent of the era of big data brings new opportunities and challenges to heritage sites. Big data has huge commercial value, especially in the aspect of application. However, the current domestic heritage site development in digital tourism cannot meet the demand of the market. Most heritage site tourism service modes are still the traditional display of ruins and print media commentary, which is difficult to realize the cultural tour service innovation.

Digital tourism development of the national archaeological site and park, Yuan Ming Yuan, is slow. Although it has an official website and official blog platform, the services it provides is mainly to push news, rather than to share communication. Tourists can only passively accept information and are unable to participate or interact. Research shows that tourists generally believe that Yuan Ming Yuan needs to improve its service level (figure 1). Tourists hope to understand the Yuan Ming Yuan panorama $(32.89 \%)$, historical beauty $(25.5 \%)$, introduction to its history $(23.49 \%)$ and legend $(15.77 \%)$. However, at present the traditional display form of interpretation can not meet the cultural tour demands of tourists.

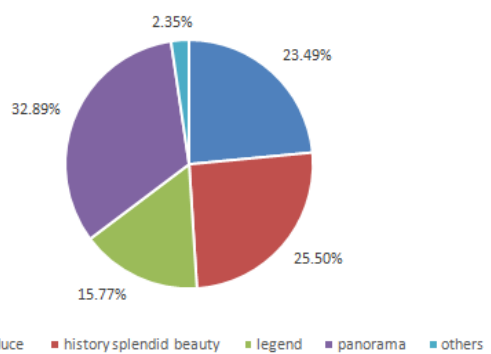

Figure 1: Visitors expectations when touring Yuan Ming Yuan

In addition, because the existing historical interpretation of Yuan Ming Yuan is not comprehensive, most tourists' perception of the Yuan Ming Yuan is inaccurate. More than $95 \%$ of Yuan Ming Yuan is ruins, so it is very difficult for tourists to understand its culture and history only visually. Consequently, nearly $92 \%$ of visitors think that Yuan Ming Yuan needs to provide mobile navigation systems (figure 2).

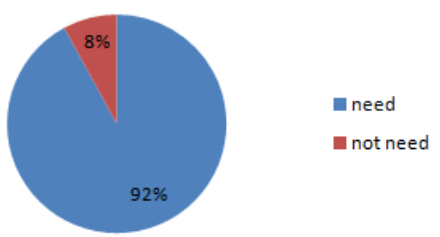

Figure 2: Tourists demand for mobile navigation system
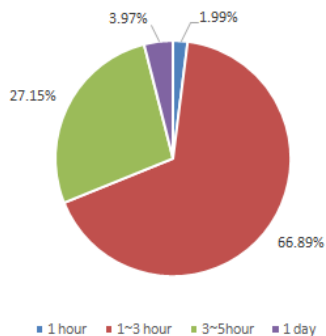

Figure 3: Viewing time of Yuan Ming Yuan Park by visitors 
About $67 \%$ of tourists who visit Yuan Ming Yuan spend about 2 to 3 hours at the site and about $27 \%$ of tourists spend 3 to 5 hours at the site (figure 3 ). However, longer visiting times did not increase the related cultural consumption. The average consumption level of tourists in Yuan Ming Yuan is only 40 Yuan and this low level of consumption proves that the heritage site has a lack of cultural consumption demand by visitors.

With the improvement of people's living standard, people are now beginning to show a pressing need for cultural tours and thus heritage site tourism presents a rising trend. Both national and local reform in China of the local culture are put forward to expand the approaches of transmitting cultural heritage and to properly handle the relationship between inheritance, development, protection and utilization in order to promote the combination of cultural heritage resources and the market as well as to promote cultural heritage information resources, digital resource development and utilization, and promote the exhibition of Chinese civilization.

As a result, under the background of big data, using the Internet, the Internet of Things, and modern technology for economic development of cultural heritage sites has a very broad market. In the era of big data a new challenge which a heritage site has to face is how to accelerate industrial innovation, form a benign competition mode and create commercial value.

\section{ONE PLATFORM-THREE SYSTEMS BASED ON BIG DATA OF HERITAGE SITES}

Big data management of smart heritage public service platforms is also applicable to all kinds of industries. It contains an abundance of materials such as pictures; characters; digital models; sound; video of the heritage site and dates from aerial photos; survey information and drawings; 3D laser scans; and other material. Through the management and analysis of the data, scenic management, 3-O (online-offline-onsite) service and digital explanation can be acquired. The platform and systems constitute a complete service circle of the scenic spot. It connects the heritage site, service, managers and tourists together thus forming the system of digital culture tourism.

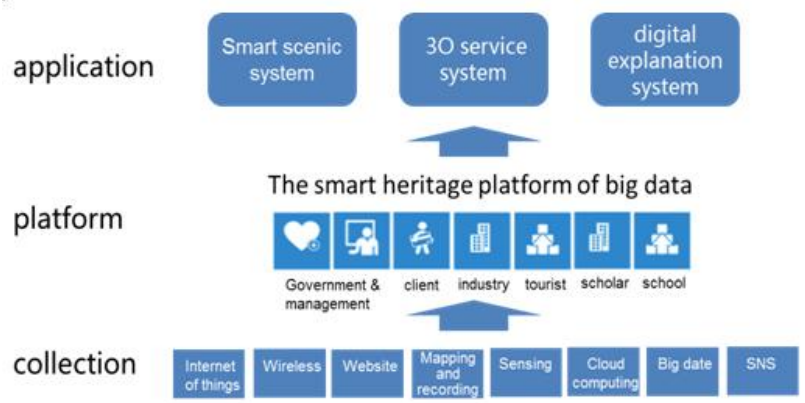

Figure 4: One platform-three systems

The One platform-three systems includes three levels: the collection level, platform level and application level (figure 4). The sources of the collection level mainly include the following aspects:

(1) Collecting information through surveying and mapping, sensing and so on. One can use advanced digital tools such as UAVs (unmanned aerial vehicles) and 3D laser scanners to collect information at the heritage site (figure 5). Additionally, one can use sensing to monitor passenger flow volume, temperature, relative humidity, and so on of the site in order to adequately protect the heritage site and improve the satisfaction of tourists (figure 6).

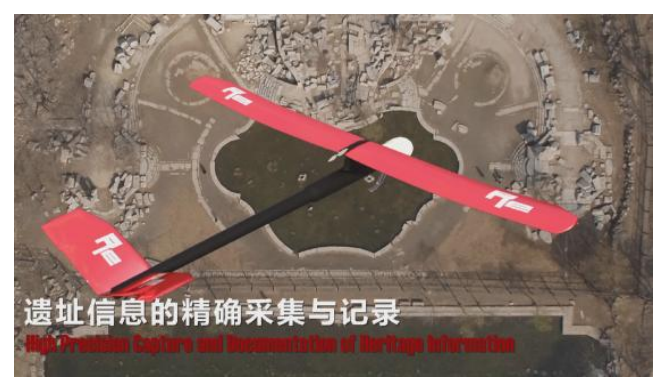

Figure 5:UVAs collect site information with high accurately

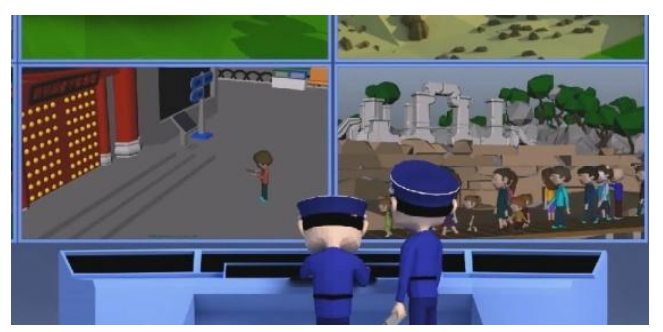

Figure 6: Sensing and monitoring information to achieve real-time control

(2) Collecting information through user's feedback, which comes from digital navigation equipment, mobile phones and so on. Lots of data such as travel time, travel route, consumer preferences, travel demand, and so on can be collected and fed back to backstage databases, which can help excavate demand of tourists and improve business income of heritage sites (figure 7).

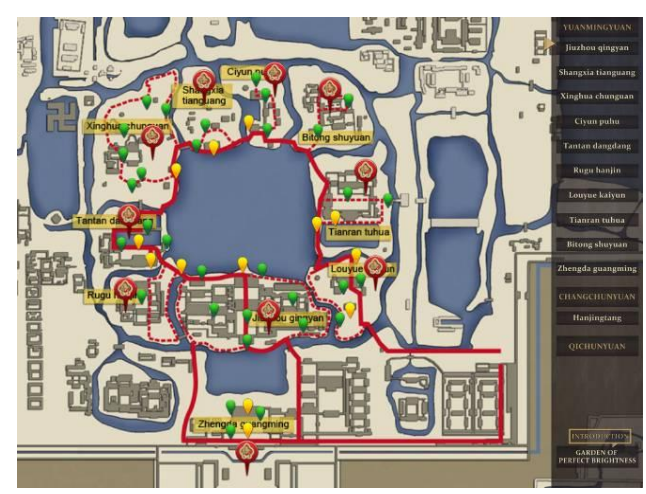

Figure 7: Digital navigation equipment collects tourist information and feeds it back to backstage databases

Besides information gathered from the site, there is lots of data from government management agencies, cultural relics protection units and so on. All the data will be collected in the smart heritage platform and service smart heritage management systems 3-O service systems and digital explanation systems, which can be accomplished using accurate acquisition, management and smart analysis.

The Smart scenic system is designed for managers. Through this system, they can control temperature, humidity and population density of the scenic spot by supervising and setting of devices; the system is also compliant for emergencies and protection of relics. The establishment and stable operation of this system will improve the conditions of cultural relics protection as well as the basic satisfaction of tourist services and the safety level of the scenic spot.

The Digital explanation system is a culture display platform for the scenic spot. It forms the direct connection between the scenic spot and the tourist and expands the exhibition form giving an additional consumption medium besides the relics. Based on in-depth historical research in combination with 
science and technology will the features of the scenic area as well as its history and culture; the building features; construction technology; and other information that the tourist might be interested in. It also enables visitors to fully understand the culture and beauty of the scenic area and highlights the significance of patriotism.

The 3-O service system can be used for experiential activities include digital performance, audio guides, education and other programs. This system integrates the experiences, feelings and online communications and enhances the diversified services; at the same time, it can improve the quality and influence of the heritage spot.

\section{INNOVATION AND APPLICATION OF INTELLECTUAL HERITAGE BASED ON BIG DATA PLATFORM}

Big data of smart heritage public service platforms contains a mass of real-time management dates, basic information of the heritage site, as well as cultural information, tourist information and consumption information. The smart heritage information can be utilized for further analysis and processing, and can be translated to valuable data for decision making as well as transformed into all kinds of digital applications.

\subsection{Innovation and application of heritage protection}

In the traditional management system of the scenic spot, we usually define the monitoring and protection functions as the main body, using fixed monitoring equipment and monitoring centers in this way. But the monitoring function can be extended to more elaborate management spaces with the linkage of digital explanation systems and management systems using terminals between tourists and managers. In this way, alarm and emergency systems can also be complete and this will greatly improve the service level and protection management of the heritage site.

\subsection{Innovation and application on heritage interpretation}

Based on the traditional centralized and decentralized digital display model, we can strengthen the linkage of design and consumption, which can translate to more allocation of cultural resources, and improve the display content and service through the analysis of visitor behavior from data collection. For example, through the analysis of the behavior characteristics of tourists' consumption, we can find the key point of cultural in public recognition, and assist in functional design through regional consumption behavior analysis of tourists. This model will help tourists to realize the display and culture of the heritage site, and also enhance the association mechanism of benign markets and services.

\subsection{Innovation and application on cultural consumption}

Based on the establishment of the 3-O service system, the service of Online-Offline-Onsite will be more dynamic. Regarding onsite, a consumer's experience will be promoted, which can also advance online and offline consumption, build brand influence and expand digital exhibition forms and cultural consumption. The system expands the limitations of traditional and single site area consumption, including experiential and online activities. Tourists can also enjoy consumption by viewing media on the website, which in turn can greatly improve the comprehensive quality and influence of heritage services, bring huge economic growth to the company.

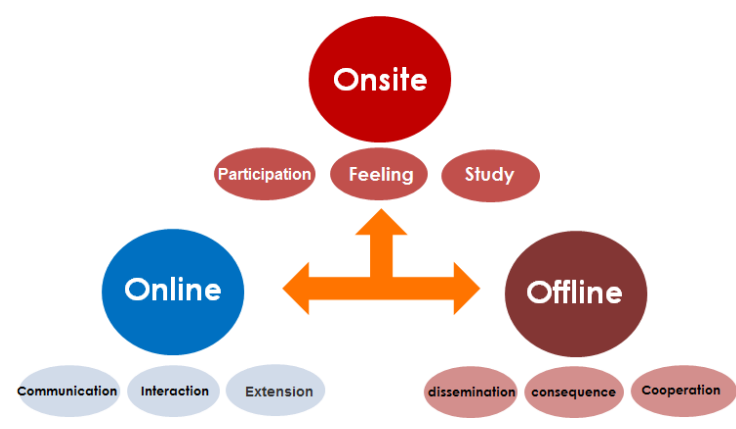

Figure 8: 3-O service model diagram

\section{INNOVATIVE APPLICATION VALUE OF SMART HERITAGE}

\subsection{Improve the utilization rate of data resources}

Using big data, rich layers of information can be built. This includes items such as mapping, sensing and wireless information. Information can not only be acquired from managers, but also from feedback and data information records from users.

Each information point can precisely collect detailed basic information and dynamically manage and analyze information on the smart heritage public service platform by using huge amounts of complex data units to acquire knowledge and insight and improve the growth of culture heritage. The technical process of getting the unknown, potential and solvable rules from big data is also through the recycling and sublimation process of culture heritage.

\subsection{Meet the cultural tour demands of tourists}

Heritage is not only technical smarts, but also humanities smarts This requires the building of smart heritage and the need to focus on people and service people, not only as the objects of intellectual legacy, but also as the main body who create smart heritage.

Based on the smart heritage public service platform , the Smart heritage management system, the 3-O service system and the digital display system, which aims to respond in a timely fashion, to effectively treat people with friendly service, can thus raise the level of digital tourism services through augmented reality experiences, improve the comprehensive service quality of cultural heritage sites, and bring long-term social benefits as well as huge economic benefits.

\section{CONCLUSION}

The application of smart heritage public service platforms on big data mixes the digital display system, the 3-O service system and the smart management system together, forming a scientific service system, by which tourists can understand the culture, legends, and history of a scenic spot, through a strong physically linked network. Tourists can see more lost heritage sites landscape at by utilizing digital applications and interpretation systems. They can also participate in a variety of cultural experiences, which increase online the consumption, transportation booking and other functions. By using the 3-O service system, visitors can easily achieve their travel, consumption and study needs, and also share their experiences and suggestions with each other, as well as have the opportunity to participate in the management and construction of scenic spots thereby becoming the direct legacy of the culture market and help to spread and inherit cultural heritage. 
ISPRS Annals of the Photogrammetry, Remote Sensing and Spatial Information Sciences, Volume II-5/W3, 2015 25th International CIPA Symposium 2015, 31 August - 04 September 2015, Taipei, Taiwan

\section{REFERENCES}

Huang Yonglin, Tan Guoxin,2012.Protection and development research on digital intangible cultural heritage. Journal of central China normal university

Yuan Guoshu , 2014. The context of large data for digital protection of intangible cultural heritage, The museums.

Report on the digital museum seminar in Beijing in 2011 The main digital museum of science and technology 